\title{
MPD Thruster Performance Analytic Models
}

\author{
James Gilland ${ }^{1}$, Geoffrey Johnston ${ }^{2}$ \\ ${ }^{1}$ OAI/NASA Glenn Research Center \\ ${ }^{2}$ Univ. of Notre Dame/NASA Glenn Research Center \\ NASA Glenn Research Center, Cleveland, OH 44142, USA \\ (440) 962-3142, james.h.gilland@grc.nasa.gov
}

\begin{abstract}
Magnetoplasmadynamic (MPD) thrusters are capable of accelerating quasi-neutral plasmas to high exhaust velocities using Megawatts (MW) of electric power. These characteristics make such devices worthy of consideration for demanding, far-term missions such as the human exploration of Mars or beyond. Assessment of MPD thrusters at the system and mission level is often difficult due to their status as ongoing experimental research topics rather than developed thrusters. However, in order to assess MPD thrusters' utility in later missions, some adequate characterization of performance, or more exactly, projected performance, and system level definition are required for use in analyses. The most recent physical models of self-field MPD thrusters have been examined, assessed, and reconfigured for use by systems and mission analysts. The physical models allow for rational projections of thruster performance based on physical parameters that can be measured in the laboratory. The models and their implications for the design of future MPD thrusters are presented.
\end{abstract}

\section{INTRODUCTION}

Magnetoplasmadynamic (MPD) thrusters have long held the promise of high exhaust velocity $\left(\mathrm{u}_{\mathrm{e}}\right)$ at MW power levels (Sovey, 1991). The combination of high $\mathrm{u}_{\mathrm{e}}$ and high power in a compact device is especially beneficial for demanding missions such as the human exploration of other planets, which will require lightweight, high power density propulsion to be feasible. At present, MPD thruster research is still at a fundamental rather than developmental level. Research goals include increasing thruster efficiency and operating lifetime. It may be safely said that current experimental MPD thrusters do not represent the refined and optimized thrusters that might be used in missions planned a generation from now, so curve fits to present data will not accurately characterize the MPD thruster of the future. In order to accurately assess their promise, a method of characterizing future thruster designs based on current knowledge of their physical behavior is needed. These characterizations are needed by system and mission analysts to assess MPD thrusters' benefits to later missions.

A secondary consideration for practical assessment of MPD capabilities is the translation of experimental data into a form suitable for system integration and parametric studies. In the laboratory, an experiment is generally operated with the thruster current and mass flow rate as the control variables, and thruster voltage and thrust as the measurements. From these variables, $\mathrm{u}_{\mathrm{e}}$, power $\left(\mathrm{P}_{\mathrm{e}}\right)$, and thrust efficiency $(\square)$ can be calculated. In contrast, a mission analyst uses $u_{e}, P_{e}$, and $\square$ to determine the trajectory and performance of a low-thrust spacecraft. A system analyst needs to derive the current, voltage, and mass of the MPD thruster from the mission $u_{e}$ and $P_{e}$ in order to then design the power system and spacecraft. Thus, MPD thruster models developed to explain thruster behavior in the laboratory must be converted to a variable space of use to system designers.

MPD experiments and theories describe MPD thrusters using variables that are relevant to experiment such as mass flow rate $(\dot{m})$ and current $(\mathrm{J})$ : 


$$
\begin{aligned}
V & =V(\dot{m}, J) \text { (measured }) \\
T & =T(\dot{m}, J) \quad \text { (measured }) \\
u_{e} & =u_{e}(\dot{m}, T)(\text { calculated }) \\
\square & =\square(\dot{m}, J, V) \text { (calculated })
\end{aligned}
$$

with the thruster geometry and plasma physics included in the relations for $\mathrm{V}$ and $\mathrm{T}$. The system model reduces the number of free variables to only 2 , from which all other parameters are derived:

$$
\begin{aligned}
& V=V\left(u_{e}, P_{e}\right) \\
& J=J\left(u_{e}, P_{e}\right) \\
& \dot{m}=\dot{m}\left(u_{e}, P_{e}\right) \\
& \square=\square\left(u_{e}, P_{e}\right) \\
& T=\dot{m} u_{e}
\end{aligned}
$$

It is important to note that in order to derive the system equations from the experimental ones, the models must be mathematically structured to allow analytical conversion from one "frame" to another. This is an artificial requirement imposed by the need for simple models to be incorporated into large, complex system or trajectory codes.

The analysis described herein consists of several parts. First, existing self-field MPD thruster models were derived using recent models for thrust production in conjunction with a voltage model that includes various known energy channels available in an MPD thruster discharge. Second, the models considered were converted using Mathematica from the experimental variable frame to the systematic frame. Any "free" parameters in the models were identified. Third, the models were compared to experimental data for two hydrogen MPD thrusters. From this data, free parameters were determined and used to assess the model over a range of operating conditions.

\section{MPD Thruster Description}

The Magnetoplasmadynamic thruster, or MPDT, is a coaxial Lorentz force accelerator. A schematic of self-field MPD operation is shown in figure 1. The thruster consists of an outer annular anode, a central cylindrical cathode, and an insulated backplate. A discharge is created between the electrodes, with current flowing from anode to cathode. The self-induced magnetic field from this current is primarily azimuthal, resulting in a $\mathrm{j}_{\mathrm{r}} \mathrm{X} \mathrm{B}_{\square}$ Lorentz force acting on the quasi-neutral plasma in the axial direction. A thruster using only the self-generated field is referred to as a "self-field" MPDT. An additional, externally generated axial magnetic field may also be imposed on the thruster in an effort to increase performance; this is referred to as an "applied-field" MPDT. The anode is typically constructed of a high temperature refractory metal such as tungsten or molybdenum. The cathode is tungsten impregnated with thorium or barium oxides to reduce the work function for electron emission. The insulating backplate is boron nitride. Propellant is injected at the rear of the thruster, or possibly along the sides, and ionized by the current flowing through the plasma in the thruster. Because the self-field thruster performance depends on the current used in the thruster, high (kiloamperes) currents are required for high specific impulse. Because the propellant must be ionized in order for the thruster to operate, propellants with low first ionization energy and high second ionization energy are predicted to give the highest efficiency. Propellants of choice for MPD thrusters are hydrogen and lithium, because of their low atomic mass and relatively low ionization energies (Ageyev, 1993 and Lapointe, 2002). Lithium's very low first ionization energy makes it particularly advantageous at lower powers $(0.5-5 \mathrm{MW})$ and moderate exhaust velocities $(20-70 \mathrm{~km} / \mathrm{s})$. Hydrogen is more amenable to multimegawatt and high specific impulse operations, is easier to supply to the thruster as a gas, and is less likely to condense on spacecraft surfaces. 


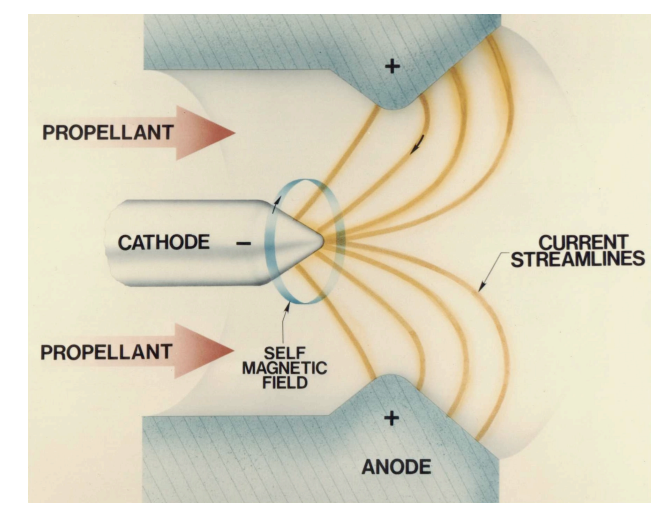

FIGURE 1. Diagram of MPD Thruster Processes. The radial current and azimuthal magnetic field produce thrust.

\section{SELF-FIELD MPD THRUSTER MODEL}

Although conceptually and often geometrically simple, MPD thrusters have been found to be rich in the complexity of the plasma flows they generate. There are several MPDT thrust models in the literature; of these, the most recent self-field models were examined for this system model: 1.) the modified Mäcker model, (Jahn, 1968, Choueiri, 1987) 2.) the Tikhonov model (Tikhonov, 1993), and 3.) an empirical model by Choueiri (Choueiri, 1998b). Each of these models have been used to model hydrogen MPD thruster data. For the model comparisons, each thrust model has been coupled to a single common voltage model. The relative strengths and weakness of each model will be evaluated, and improvements will be suggested.

The voltage model used with all three thrust models considers various energy partitions possible in the plasma.:

$$
V=\frac{\mathrm{T}^{2}}{2 \dot{\mathrm{m} J}}(1+\square)+\frac{\dot{m} \square_{i}}{\mathrm{~J}} g_{i}+\frac{\mathrm{J} \mathrm{f}}{\square}+\mathrm{Vf}_{\mathrm{f}}
$$

The first term represents the directed kinetic energy voltage due to the acceleration of the plasma; a divergence term ( $\square$ ) was added to represent the thrust losses due to the divergence of the plasma flow, which reduces effective thrust. The power required to ionize the plasma is modeled as an ionization energy per kilogram ( $\square$ ) for the propellant. Depending upon the MPD thrust model assumed, the ionization fraction may vary with the exhaust velocity or current. Specifically, some models have the ionization fraction linearly proportional to the current at low currents; this variation is signified by the $g_{i}$ term. A heuristic ohmic heating term ( $\mathrm{J} / \square$ ) is included, with the geometric factor "f" to account for varying thruster geometries. In later comparisons, a $\square$ value of one-tenth Spitzer conductivity was used to account for anomalous resistivity observed in MPD thrusters (Choueiri, 1993). The geometric term, f, was approximated as $\ln \left(\mathrm{r}_{\mathrm{a}} / \mathrm{r}_{\mathrm{c}}\right) /(2 \square \mathrm{L})$ to give some variation in ohmic losses depending on thruster dimensions. Finally, electrode and sheath potentials representing power deposited to the cathode and anode are represented simplistically by a constant "fall" voltage, $\mathrm{V}_{\mathrm{f}}$. This term is the only "free" parameter in the models (apart from ionization loss, to be discussed later) consists of the sum of the plasma sheath voltages at both anode and cathode, and was observed to be thruster dependant. The term ranges from $50-150 \mathrm{~V}$ and is empirically determined to best fit the data. However, experimental tests have demonstrated (Myers, 1992) that there is a physical basis for this fall voltage term, and that each thruster has its own characteristic fall voltage. 


\section{Modified Mäcker Model}

The Mäcker formula is the most basic description of thrust generation by an MPD thruster. The relation calculates the J X B Lorentz force for coaxial cylindrical electrodes, assuming azimuthal uniformity, purely radial current except at the cathode tip, and a simplified axial distribution current along the cathode. The model takes the form

$$
T=b J^{2}
$$

The coefficient " $b$ " is related to the thruster electrode geometry:

$$
\mathrm{b}=\frac{\square_{0}}{4 \square} \ln \frac{\square_{\mathrm{r}_{\mathrm{a}}}}{\mathrm{r}_{\mathrm{c}}}+\square[
$$

where $r_{a}$ is the thruster anode radius, $r_{c}$ is the central cathode radius, and $\square$ is a term accounting for thrust contributions from the cathode tip (Jahn, 1968). This model was initially used by researchers to describe MPDT thrust over the full range of currents and mass flow rates; however, subsequent thrust measurements showed that the thrust departed from this model at low values of current and exhaust velocity (Gilland, 1987). A later theory by Choueiri (Choueiri, 1987) divided MPDT thrust behavior into super- and sub-Alfven critical speed operating regimes, with different thrust - current relationships in each regime. The Alfven critical speed $\left(U_{A}\right)$ is the velocity where the kinetic energy of ions in the propellant is equal to the first ionization energy of the neutral atom:

$$
U_{A}=\sqrt{\frac{2 \square_{i}}{M_{i}}}
$$

According to this model's interpretation, the propellant is only partially ionized in the sub-Alfven regime. The model assumes that there is a linear relation between current and ionization fraction in the plasma up to the current and mass flow rate at which the plasma is fully ionized, $\mathrm{J}_{\mathrm{fi}}$ :

$$
\mathrm{J}_{\mathrm{fi}}=\sqrt{\frac{\dot{\mathrm{m}} \mathrm{U}_{\mathrm{A}}}{\mathrm{b}}}
$$

This allowance for different thrust profiles at super- and sub-Alfven critical speed necessitates a continuous, piecewise function for thrust:

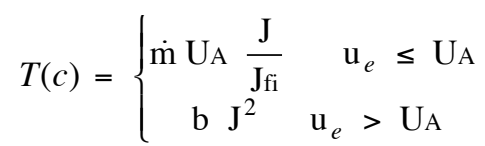

The modified Mäcker thrust model developed for this paper takes the traditional form at super-Alfven critical speeds but uses the partially ionized model below. Because of the piecewise nature of the thrust model, the voltage model was defined for the two different regimes to accommodate the partially ionized plasma at currents below $\mathrm{J}_{\mathrm{fi}}$ :

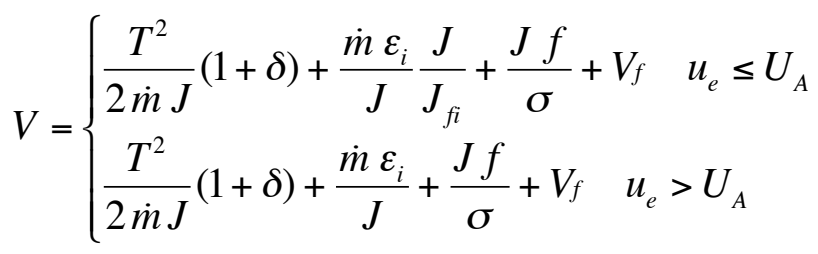




\section{Tikhonov Model}

The Tikhonov (1993) thrust model is very similar to the modified Mäcker model discussed above. The primary difference between the two models is that the Tikhonov thrust model attempts to operate with only one thrust equation over the full range of current/exhaust velocity:

$$
T=\stackrel{\sqcup}{\square} b+\frac{\square}{\left(J^{2} / \dot{m}\right)^{2}} \bigsqcup_{\square} \mathrm{J}^{2}
$$

The parameter $\square$ is a geometry and propellant dependent constant. The $\square$ term in the thrust model decreases in magnitude as the discharge current increases, and so there would be a major divergence between the Tikhonov and the modified Mäcker models only at very small $\mathrm{J}$ or equivalently, $\mathrm{u}_{\mathrm{e}}$. In fact, the $\square$ term begins to have an impact on net thrust for $\mathrm{H}_{2}$ propellant only very far below sub-Alfven critical speeds.

\section{Empirical Model}

The empirical model takes an approach similar to the Tikhonov model, but relies on phenomenological observations to match the experimental data, rather than fundamental theories (Choueiri, 1998a):

$$
T=\frac{\square}{\square^{4}}+\ln \frac{\square r_{a}}{\square r_{c}}+\square^{2} \stackrel{\square}{\square}
$$

The dependence on $U_{A}$ is maintained by the term $\square=J / J_{\mathrm{fi}}$. The increase in $T / \mathrm{J}^{2}$ at low currents is modeled by the $\square^{4}$ term. $\square$ is an empirical constant that appears to be dependent on propellant species and mass flow rate. It should be noted that Choueiri found the original model did not accurately reproduce experimental results with hydrogen, possibly because of the variability in defining the Alfven critical speed and therefore the $\square$ parameter for a molecular propellant.

\section{RESULTS}

Since these models take a systems analysis point of view, each model had to meet two criteria. First, that the equation set could be analytically transformed into system variables. Second, that the resulting model could match experimental efficiencies and voltage vs. current data. Using Mathematica, the three models were converted to the systems frame and compared to data from the Princeton Benchmark thruster (Choueiri, 1998b) and the Osaka MYII thruster (Tahara,1985), varying the free parameter of $\mathrm{V}_{\mathrm{f}}$ to best fit the experimental curves.

Upon mathematical evaluation, the Tikhonov model was not useful because it failed to produce real (non-imaginary) results at sub-Alfven critical speed if the fall voltage was kept constant over the whole range of specific impulses. Assuming that the fall voltage parameter was allowed to change, the model was able to produce real data for subAlfven critical speeds, but was unable to accurately track the Princeton benchmark data that was used as comparison. Thus, to use this model effectively for systems analysis, one requirement would be a new voltage model that could account for a variable fall voltage. In addition, the overall effect of the $\square$ term was to scale the thrust with $\mathrm{J}^{\square^{2}}$ only at low $\mathrm{u}_{\mathrm{e}}(<10 \mathrm{~km} / \mathrm{s})$, an effect that is difficult to observe in any experimental data due to the difficulty of operating at very low discharge currents. From the systems analysis perspective, this effect was determined to be insignificant; few missions can be envisioned which require operation at the $\mathrm{u}_{\mathrm{e}}$ 's at which the additional term becomes important. For these reasons, as well as the fact that the Tikhonov expression so closely tracked the Mäcker model at super-Alfven speeds, and because of the extremely long compiling times needed to reliably run the model, this model was not selected for further testing.

The empirical thrust model in conjunction with the assumed form of the voltage equation was found to be nonanalytic in terms of converting from an experimental to a system level formulation. In an attempt to approximate the model to allow for the experiment-to-system conversion, a first order Taylor expansion of the original thrust model was tried. This approximation was in good agreement with data presented by Choueiri (Choueiri, 1998b) and 
reproduced the relevant features of the model. The empirical mode proved to be virtually identical to the modified Mäcker model over a wide range of power and $u_{e}$; primary differences occurred at $u_{e}$ less than $10 \mathrm{~km} / \mathrm{s}$, which is generally below the range of interest to mission designers. The model's inaccuracy in reproducing hydrogen data resulted in its rejection as a basis for a system model.

The Mäcker model was convertible to a system frame, although the resulting models are piecewise continuous and must be defined in two regimes. The representative equations from the modified Mäcker model for $J\left(u_{e}\right)$, $\mathrm{V}\left(\mathrm{u}_{\mathrm{e}}\right), \mathrm{T}\left(\mathrm{u}_{\mathrm{e}}\right), \mathrm{m}\left(\mathrm{u}_{\mathrm{e}}\right)$ and $\square\left(\mathrm{u}_{\mathrm{e}}\right)$ are shown here for the two operating regimes described previously.

For $\mathrm{u}_{\mathrm{e}}<\mathrm{U}_{\mathrm{A}}$, the model equations are given with the annotation "l" to denote sub-Alfven critical speed operation:

$$
\begin{aligned}
& J l\left(u_{e}\right)=\frac{1}{\mathrm{Ua}} \sqrt{2} \mathrm{c} \sqrt{\frac{\left(\mathrm{Ua}^{2} \square\left(2 \mathrm{bPe} \square \square+u_{e}\left(2 \mathrm{fPe}+\left(\mathrm{Vf}^{2}+\mathrm{bPe} \mathrm{Ua}(1+\square)\right) \square\right) \square \square\right)\right)}{u_{e}\left(2 \mathrm{~b} \square \square+u_{e}(2 \mathrm{f}+\mathrm{b} \mathrm{Ua}(1+\square) \square)\right)^{2}}} \\
& V\left(u_{e}\right)=\frac{\sqrt{2}\left(u_{e} f+b \square \square\right)}{U a \square \sqrt{u_{e}\left(2 b \square \square+u_{e}(2 f+b U a(1+\square) \square)\right)^{2}}} \sqrt{\left(U a^{2} \square\left(2 b P e \square \square+u_{e}\left(2 f P e+\left(V f^{2}+b P e U a(1+\square)\right) \square\right) \square \square\right)\right)} \\
& +\frac{1}{2} \underset{\square}{\stackrel{\square}{[} V f} V f+\sqrt{2} b u_{e}(1+\square) \sqrt{\frac{\left(U a^{2} \square\left(2 b P e \square \square+u_{e}\left(2 f P e+\left(V f^{2}+b P e U a(1+\square)\right) \square\right) \square()\right)\right.}{u_{e}\left(2 b \square \square+u_{e}(2 f+b U a(1+\square) \square)\right)^{2}}} \frac{G}{\square} \\
& m l\left(u_{e}\right)=\frac{2 \mathrm{bUa} \square\left(2 \mathrm{~b} \operatorname{Pe} \square \square+u_{e}\left(2 \mathrm{fPe}+\left(\mathrm{Vf}^{2}+\mathrm{b} \operatorname{Pe} \mathrm{Ua}(1+\square)\right) \square\right) \square \square\right)}{u_{e}\left(2 \mathrm{~b} \square \square+u_{e}(2 \mathrm{f}+\mathrm{bUa}(1+\square) \square)\right)^{2}} \\
& \square l\left(u_{e}\right)=\frac{\mathrm{b} u_{e} \mathrm{Ua} \square\left(\left(2 \mathrm{bPe} \square \square+u_{e}\left(2 \mathrm{fPe}+\left(\mathrm{Vf}^{2}+\mathrm{b} \operatorname{Pe} \mathrm{Ua}(1+\square)\right) \square\right) \square \square\right)\right.}{\operatorname{Pe}\left(2 \mathrm{~b} \square \square+u_{e}(2 \mathrm{f}+\mathrm{b} \mathrm{Ua}(1+\square) \square)\right)^{2}}
\end{aligned}
$$

where

$$
\square=\sqrt{u_{e}} \text { Vf } \sqrt{\square} \sqrt{4 \mathrm{bPe} \square \square+u_{e}\left(4 \mathrm{fPe}+\left(\mathrm{Vf}^{2}+2 \mathrm{bPe} \mathrm{Ua}(1+\square)\right) \square\right)}
$$

Similarly for $\mathrm{u}_{\mathrm{e}}>\mathrm{U}_{\mathrm{A}}$, using the annotation "h":

$$
J h\left(\mathrm{u}_{\mathrm{e}}\right)=\frac{-\mathrm{u}_{\mathrm{e}} \operatorname{Vf} \square+\sqrt{\mathrm{u}_{\mathrm{e}}} \sqrt{\square} \sqrt{2 \mathrm{bu}_{\mathrm{e}}{ }^{2} \operatorname{Pe}(1+\square) \square+4 \mathrm{bPe} \square \square+\mathrm{u}_{\mathrm{e}}\left(4 \mathrm{fPe}+\mathrm{Vf}^{2} \square\right)}}{2 \mathrm{u}_{\mathrm{e}} \mathrm{f}+\mathrm{bu}_{\mathrm{e}}{ }^{2}(1+\square) \square+2 \mathrm{~b} \square \square}
$$




$$
\begin{gathered}
V h\left(\mathrm{u}_{\mathrm{e}}\right)=\square \frac{\operatorname{Pe}\left(2 \mathrm{u}_{\mathrm{e}} \mathrm{f}+\mathrm{bu}_{\mathrm{e}}{ }^{2}(1+\square) \square+2 \mathrm{~b} \square \square\right)}{\mathrm{u}_{\mathrm{e}} \operatorname{Vf} \square-\sqrt{\mathrm{u}_{\mathrm{e}}} \sqrt{\square} \sqrt{2 \mathrm{bu}_{\mathrm{e}}^{2} \operatorname{Pe}(1+\square) \square+4 \mathrm{~b} \operatorname{Pe} \square \square+\mathrm{u}_{\mathrm{e}}\left(4 \mathrm{fPe}+\mathrm{Vf}^{2} \square\right)}} \\
m h\left(\mathrm{u}_{\mathrm{e}}\right)=\frac{2 \mathrm{~b} \square\left(\left(\mathrm{bu}_{\mathrm{e}}^{2} \operatorname{Pe}(1+\square) \square+2 \mathrm{~b} \operatorname{Pe} \square+\mathrm{u}_{\mathrm{e}}\left(2 \mathrm{fPe}+\mathrm{Vf}^{2} \square\right)\right) \square \square\right)}{\left(2 \mathrm{u}_{\mathrm{e}} \mathrm{f}+\mathrm{bu} \mathrm{u}_{\mathrm{e}}^{2}(1+\square) \square+2 \mathrm{~b} \square \square\right)^{2}} \\
\square h\left(\mathrm{u}_{\mathrm{e}}\right)=\frac{\mathrm{bu}_{\mathrm{e}}^{2} \square\left(\mathrm{bu}_{\mathrm{e}}^{2} \operatorname{Pe}(1+\square) \square+2 \mathrm{~b} \operatorname{Pe} \square \square+\mathrm{u}_{\mathrm{e}}\left(2 \mathrm{fPe}+\mathrm{Vf}^{2} \square\right) \square \square\right)}{\operatorname{Pe}\left(2 \mathrm{u}_{\mathrm{e}} \mathrm{f}+\mathrm{bu}_{\mathrm{e}}^{2}(1+\square) \square+2 \mathrm{~b} \square \square\right)^{2}}
\end{gathered}
$$

where

$$
\square=\sqrt{\mathrm{u}_{\mathrm{e}}} \mathrm{Vf} \sqrt{\square} \sqrt{2 \mathrm{bu}_{\mathrm{e}}^{2} \operatorname{Pe}(1+\square)+4 \mathrm{~b} \operatorname{Pe} \square \square+\mathrm{u}_{\mathrm{e}}\left(4 \mathrm{fPe}+\mathrm{Vf}^{2} \square\right)}
$$

In each case the fall voltage for each model was adjusted so that mass flow, current, voltage, and efficiency all fit best at a reference point; however, once the fall voltage was determined for each model and thruster, it was left constant over the full course of operation. $\mathrm{P}_{\mathrm{e}}$ and $\mathrm{u}_{\mathrm{e}}$ were input directly from experimental data. One outstanding issue in modeling thrust was the value of $\square$ to be used in the thrust coefficient definition. Common values range from 0.25 to 0.75 (Jahn, 1968). In the course of this study, values of 0.0 to 0.75 were considered; a value of $\square=0.75$ was found to give the best agreement with data. Table 1 indicates the relevant parameters used in the simulations. The two thrusters considered are shown in Figure 2.

TABLE 1. Relevant Modeling Parameters for MYII and Princeton Benchmark (PBT) Thrusters Considered in System Model.

\begin{tabular}{|c|c|c|c|}
\hline Thruster & $\mathrm{r}_{\mathrm{a}} / \mathrm{r}_{\mathrm{c}}$ & Prop & Mäcker $\mathrm{V}_{\mathrm{f}}$ \\
\hline MY II & 3.8 & $\mathrm{H}_{2}$ & 80 \\
\hline PBT & 5.4 & $\mathrm{H}_{2}$ & 150 \\
\hline
\end{tabular}

The modified Mäcker model matched PBT experimental data well for a wide range of specific impulses. Figure 3 shows a comparison of the modified Macker thrust model with experimental data from the two thrusters considered in this study. The "effective b" on the abscissa is simply thrust divided by the square of the current. In the case of

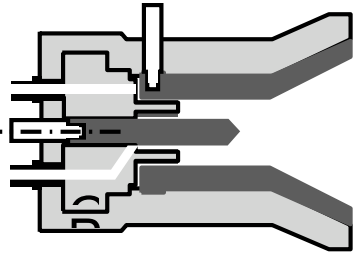

(a)

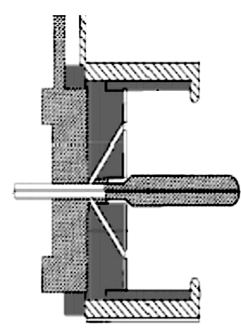

(b)

FIGURE 2. Schematics of a.) MYII Thruster (Tahara, 1985) and b.) Princeton Benchmark Thruster (Choueiri, 1998b) (Drawings are not to scale). 


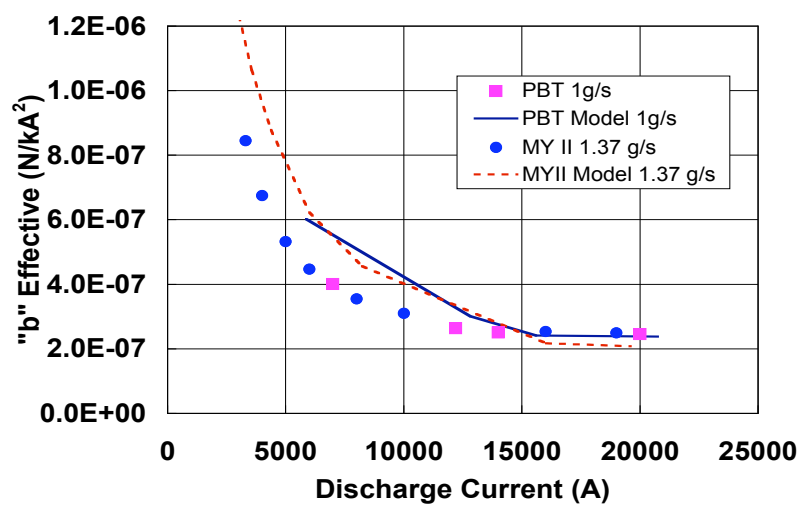

FIGURE 3. Comparison of Modified Mäcker Model with Thruster Data at both Low and High Power Levels.

the model, this value is by definition a constant above $\mathrm{J}_{\mathrm{fi}}$, and follows a $\mathrm{J}^{-1}$ behavior below $\mathrm{J}_{\mathrm{fi}}$. The data for the two thrusters show similar but not identical increase with low J. As has been observed by several researchers (Choueiri, 1987; Fischer, 1985), the exact value of the Alfven critical speed is difficult to specify for a molecular propellant, so that the point at which an actual thruster transitions from fully to partially ionized may not be clearly marked. The thrust behavior near $\mathrm{J}_{\mathrm{fi}}$ may therefore not be strictly proportional to $\mathrm{J}^{-1}$. However, the model and thruster behavior appear to follow each other qualitatively in the partially ionized regime. The difference in thrust versus current stems from the failure of the full model (thrust, voltage, current, mass flow rate) to simultaneously match all of the experimental parameters.

A direct comparison of model and data voltage-current characteristics for the PBT is shown in Figure 4, and of efficiency- $\mathrm{u}_{\mathrm{e}}$ in Figure 5. The change in slope of the curves is the point at which $\mathrm{J}=\mathrm{J}_{\mathrm{fi}}$. A difficulty in comparing the model with PBT hydrogen data is the large voltage fluctuations observed in the experiment. The values used in Figures 4 and 5 are the mean values. The model follows the current-voltage behavior of the Princeton thruster reasonably well, particularly at high current levels. The model appears to over-predict thruster efficiency by approximately $5 \%$ (i.e., the model efficiency in percent is $5 \%$ greater than the measured values). Figure 5 represents the data that would be used in calculating optimal trajectories; for scoping and system assessments, the model appears to duplicate MPD behavior reasonably well.

Calculations for the MYII thruster using hydrogen propellant yielded less accurate results. Thruster and model

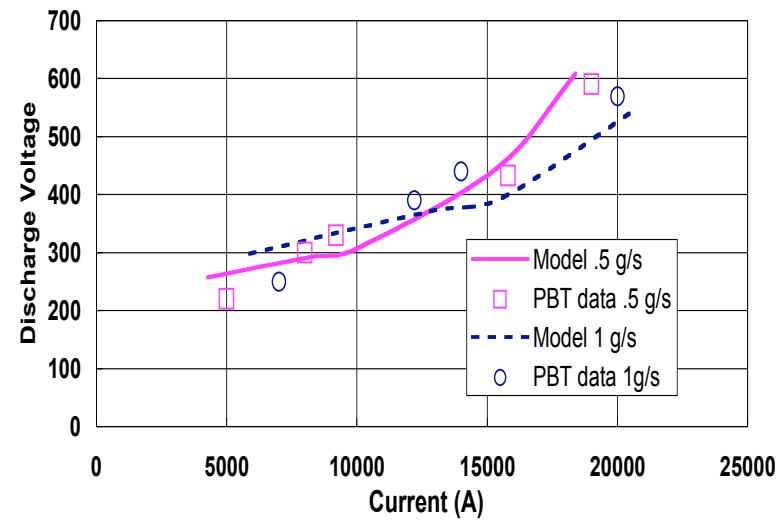

FIGURE 4. $\mathrm{H}_{2}$ PBT Terminal Voltage Characteristics and Model Results for Two Mass Flow Rates.

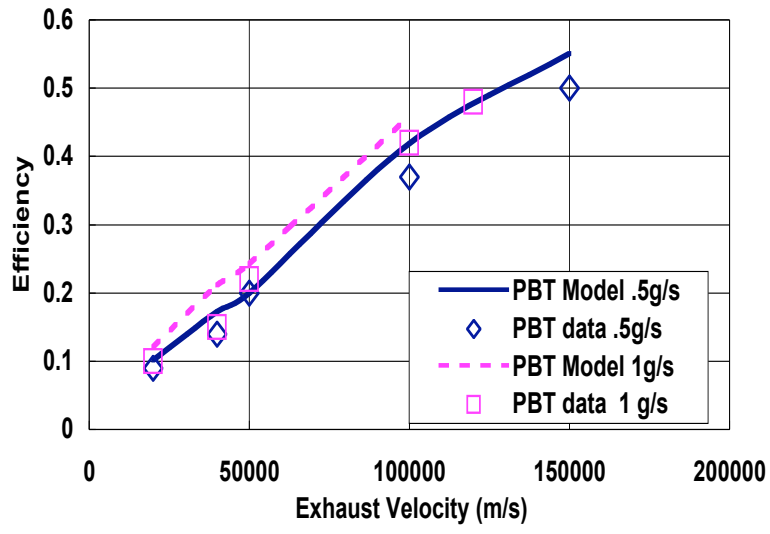

FIGURE 5. $\mathrm{H}_{2}$ PBT Mission Performance Characteristics and Model Results for Two Mass Flow Rates. 


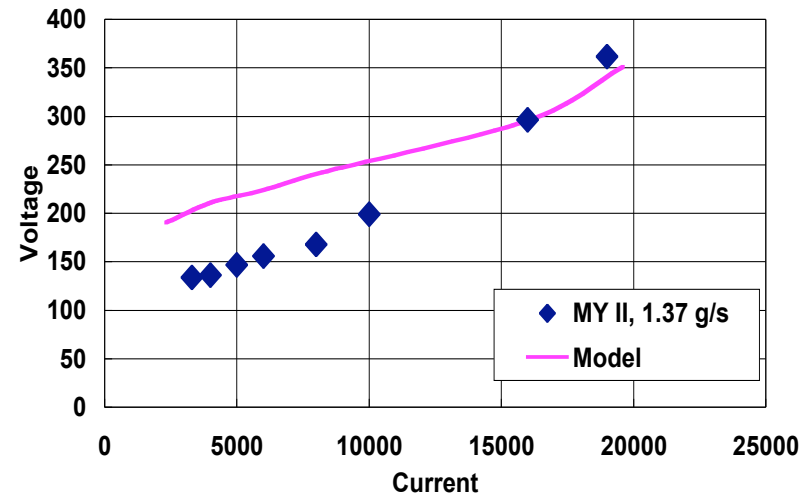

FIGURE 6. MYII Terminal Characteristics (Tahara 1985) and Model Results (model shows poor agreement at low currents (below $\left.\mathrm{J}_{\mathrm{fi}}\right)$ ).

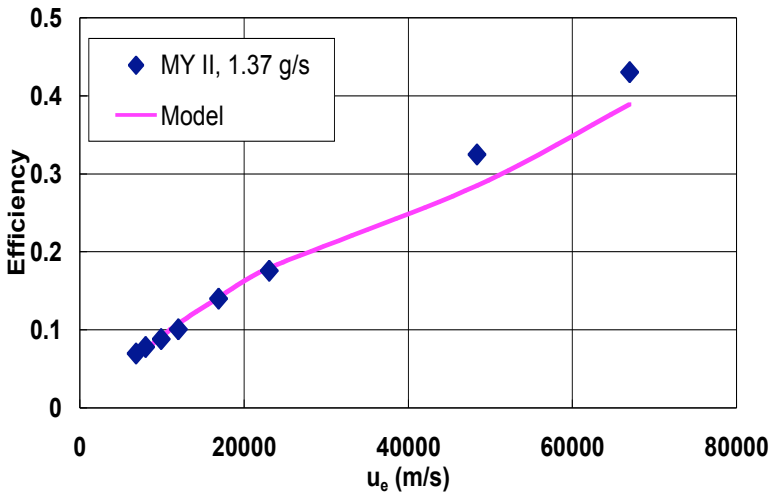

FIGURE 7. MYII Mission Performance Model Shows Good Agreement with Performance Measurements.

voltage characteristics are shown in Figure 6. The model diverges from experimental behavior by as much as $25 \%$ at low currents and powers, but closely agrees near and above $\mathrm{J}_{\mathrm{fi}}$, which would be $19 \mathrm{kA}$ for this thruster and mass flow rate. Because the MYII has a smaller discharge chamber than the PBT and was run at higher mass flow rates, additional ionization, excitation, and recombination processes may be occurring in the thruster, particularly at low $\mathrm{u}_{\mathrm{e}}$. Specifically, recovery of some of the ionization energy from the plasma flow would reduce the amount of frozen flow energy convected with the plasma and result in a lower voltage for a given $u_{e}$. This effect has also been observed in MACH2 calculations simulating the same thruster (Mikellides, 2001). In contrast, the modeled mission performance shown in Figure 7 agrees quite well with the data and could also be used in a mission analysis of this type of MPD thruster. However, it is clear that the processes occurring below $\mathrm{U}_{\mathrm{A}}$ in the MYII thruster are more complex than assumed in the current model.

\section{CONCLUSIONS}

The model described above offers some initial descriptions of MPD thrusters on a system level, and provides some insight into some of the physical processes occurring in the MPD plasma. The first goal of this study, to generate a MPD thruster performance model suitable for use in system or mission analysis, has been achieved. More important than the accuracy of the model in reproducing experimental results is the fact that the model can be modified in terms of scientifically relevant parameters, such as fall voltage, ionization energy of the propellant, and thruster dimensions. This will allow the user to assess the benefit of fundamental improvements to MPD thruster behavior, such as reducing the fall voltage, to project possible performance improvements over a range of powers and exhaust velocities.

In comparing and deriving the parameters needed to match the model to experimental results, some insight has been gained into the validity of the assumptions. The assumed form of the voltage model used in the set of equations imposes the greatest uncertainty in deriving a unified model of the MPD discharge. Of the assumed constant parameters in the model $-\mathrm{G}, \mathrm{b}, \mathrm{V}_{\mathrm{f}}-$ two arise from the voltage equation. The relative fidelity of the model to PBT data compared to that of the MYII data implies a marked difference in the behavior of these two devices over a range of power. The simple assumptions of constant ionization energy, constant fall voltage, and constant thrust coefficient followed PBT behavior relatively well. Some or all of these assumptions break down when modeling the MYII.

Some additional aspects of MPD performance have not yet been addressed with this model. Not yet assessed in this model is the effect of propellant species. Different propellants can be modeled using this formulation, with the difference in species factoring in to the definition of $U_{A}$, as well as in the ionization energy. The other species most often used in MPD thrusters are argon and lithium. Both of these propellants have much lower Alfven critical 
speeds, and much of their operating regime would then be essentially described using the Mäcker formula. The accuracy of the assumptions of constant parameters in the voltage model will have to be assessed for each of these propellants. Similarly, the thruster operating limit known as onset has not been incorporated into the model. Onset is usually associated with increased voltage fluctuations, and anode erosion. A model for this process could be included as a limit on $\mathrm{u}_{\mathrm{e}}$ or current in the equations. Finally, the addition of an applied magnetic field to the model would allow extension to both types of MPD thruster.

\section{REFERENCES}

Ageyev, V.P., et al., "High-Current Stationary Plasma Accelerator of High Power," in Proc. 23 ${ }^{\text {rd }}$ International Electric Propulsion Conference, IEPC-93-117, Seattle, WA, 13-16 September 1993.

Choueiri, E. Y. and Okuda, H., "Anomalous Ionization in the MPD Thruster," in Proc. $23^{\text {rd }}$ International Electric Propulsion Conference, IEPC-93-067, Seattle, WA, 13-16 September 1993.

Choueiri, E. Y. and Ziemer, J. K., "Quasi-Steady Magnetoplasmadynamic Thruster Performance Database," presented at $34^{\text {th }}$ Joint Propulsion Conference, AIAA-98-3472, Cleveland, OH, July 13-16, 1998 b.

Choueiri, E. Y. et al., "MPD Thruster Instability Studies," AIAA-87-1067, September 1987.

Choueiri, E. Y., "Scaling of Thrust in Self-Field Magnetoplasmadynamic Thrusters,"J. Propulsion and Power 14, 744-753 (1998a).

Fischer, E. et al., "Self-Field MPD Thruster with Atomic and Molecular Propellants," Appl. Phys. B 38, 41-49, (1985)

Gilland, J. H. et al., "MPD Thruster Scaling," presented at $19^{\text {th }}$ International Electric Propulsion Conference, AIAA-87-0997, Colorado Springs, CO, 1987.

Jahn, R. G. Physics of Electric Propulsion, McGraw-Hill, New York, 1968, pp. 240-245.

Lapointe, M.R. and Mikellides, P.G., "Design and Operation of MW-Class MPD Thrusters at the NASA Glenn Research Center," presented at $38^{\text {th }}$ Joint Propulsion Conference, AIAA-2003-4133, Indianapolis, IN, 7-10 July 2002.

Mikellides, P. G., "Design and Operation of MW-Class MPD Thrusters-Part I: Numerical Modeling,' presented at $27^{\text {th }}$ International Electric Propulsion Conference, IEPC-01-124, Pasadena, CA 14-19 October, 2001.

Myers, R. M. "Scaling of $100 \mathrm{~kW}$ Class Applied-Field MPD Thrusters," presented at $28^{\text {th }}$ Joint Propulsion Conference, AIAA92-3462, Nashville, TN, July 6-8 1992.

Sovey, J. and Mantenieks, M., "Performance and Lifetime Assessment of Magnetoplasma-dynamic Arc Thruster Technology," J. Propulsion. and Power, 7, 71-83, 1991.

Tahara, H., Kagaya, Y. and T. Yoshikawa, "Quasi-Steady MPD Arcjets with Applied Magnetic Fields," presented at $18^{\text {th }}$ International Electric Propulsion Conference, AIAA-85-2001, September 30-October 2, Alexandria, VA, 1985.

Tikhonov, V. B. et al., "Research of Plasma Acceleration Processes in Self-Field and Applied Magnetic Field Thrusters," in Proc. $23^{\text {rd }}$ International Electric Propulsion Conference, IEPC-93-076, Seattle, WA, 13-16 September 1993. 